\title{
Translation of Social Dialect in Frog from the Perspective of Prominence in Construal Theory
}

\author{
Yu-Shan ZHAO ${ }^{1, a,{ }^{*}}$, Ya-Nan XU ${ }^{1, b}$ \\ ${ }^{1}$ School of Foreign Languages, North China Electric Power University, Beijing, China. \\ azhaoyushan1963@163.com ${ }^{b}$ mier1452@163.com \\ *Corresponding author
}

Keywords: Construal theory, Prominence, Frog, Social dialect, Translation.

\begin{abstract}
Frog is one of the well-known works of Mo Yan who won the $8^{\text {th }}$ Mao Dun Literary Prize, which is full of social dialect. A suitable translation of social dialect is conducive to the appreciation of this novel by western readers. This paper aims to analyze the translation of social dialect in Mo Yan's novel Frog from the perspective prominence dimension of Construal theory in order to prove that prominence dimension of Construal theory is feasible for the translation of social dialect. According to prominence, different people have different construal ways for the same object owing to the different prominent habit, but the content is still the same. With the suitable prominence as the guidance, translator can construe well the social dialect and offer the target readers a remarkable translation version through the application of suitable translation methods, such as literal translation, liberal translation, transliteration, and so on.
\end{abstract}

\section{Introduction}

Mo Yan, an important writer in the history of Chinese literature, is the first writer in China to win the Nobel Prize for Literature in 2012, and it is conducive to the introduction of Chinese literature to the world. As the first Chinese writer to win the Nobel Prize for Literature, what helps his works to be known in the world is the translation. Mo Yan expresses his appreciation to his translators for many times, because he believes that literature is just the literature of all kinds of languages without the creative work of the translators and it is their translation versions that make the literature become the international literature [1].

Actually, many translation scholars have carried on their researches on the translation of Mo Yan's novels from multiple aspects with the application of various theories, such as the Rewriting Theory, the Skopos Theory, the Relevance Theory, the Eco-translatology theory and so on. Based on the studies of translation scholars, it is obvious that Construal Theory is barely to be adopted for the study of the translation of Mo Yan's novel. Consequently, the paper aims to study the translation of Mo Yan's novel from the perspective of prominence dimension in Construal Theory with social dialect as the study object, for social dialect is one of the main features of Mo Yan's novels affected by different factors, such as education background, social status, age, gender and other aspects. The paper chooses examples from the Goldblatt's translation version Frog, one of well-known works of Mo Yan with various social dialects, and demonstrates that prominence dimension in Construal theory is applicable in the guidance of the translation of social dialects in Mo Yan's novel.

\section{Social Dialect and Frog}

Social dialect, one category of dialects, is the significant feature of the novel Frog, which is helpful for the appreciation of this novel. And its translation can be helpful for the western readers comprehending the novel. Therefore, the paper aims to study the translation of social dialect based on the examples selected from the novel Frog.

\section{Dialect}

Dialect is the result of language differentiation, a linguistic variety with particular characteristics in 
respect of sound, vocabulary and grammar, such as the dialect in North China, south of Fujian Province, and Cantonese [2]. Many linguists have made the researches on the dialect and categorized it in different ways. According to Catford [3], dialect can be divided into four categories, that is, geographical dialect, temporal dialect, social dialect and idiolect based on the user of language. Dialect carries a great deal of information about the speaker, such as the identification, the hometown, the age, the gender and so on. The paper mainly carries out the study of the social dialect in Frog.

\section{Social Dialect}

Social dialect emerges in response to social stratification within a speech community [4], which are influenced by all kinds of factors, such as social class, religion, age group, ethnicity or other social characteristic, which can easily be recognized in the community. Such factors as these do appear to be related fairly directly to how people speak [5]. For instance, dialects are different between different ages. The infancy tends to speak simple languages, which is lacking of the change of register of language; the younger is apt to the pursuit of the fashionable expressions; while the expressions of the elderly are usually out-dated and conservative.

\section{Frog}

In August, 2011, Mo Yan won the $8^{\text {th }}$ Mao Dun Literary Prize for his work Frog. With nearly sixty-year ups and downs of rural childbearing history of new China as the background, the novel describes the life experience of a female country doctor who has experienced in gynecology for 50 years. The novel vividly shows the arduous and complicated historical process of controlling the rapid increase of population and carrying on the family planning policy and creates a moving image of rural gynecologist at the same time.

In the novel of Frog, many social dialects should be valued greatly for the purpose of the comprehension of this novel's character and theme.

\section{Prominence of Construal Theory}

Based on different ways of construal, different expression ways can be produced, which can be the explanation of the diversity of the language. Translation, in essence, is also a process of cognition, involving the understanding of the original and the production of the target language text. According to Langacker, construal refers to the capacity of construing the same situation in different ways, including five aspects, that is, specificity, domain, background, perspective, and prominence [6].

In viewing a scene, which part of this scene that we pay more attention to is the prominent part, and the prominent part is selected out by our attention from the ground. The famous face/vase illusion picture can be considered as the example of the relationship between figure and ground. One can see two possible things by looking at this picture, vase or two faces, and one can only notice one of them once, which is called the phenomenon of figure and ground. The thing perceived as the figure usually have the relatively complete form and structure, which is easy to be identified and memorized [7]. Different expressions can have the same content and describes the same relationship, while the semantic meaning is different due to the different choices of figure and ground.

In relational predication, different prominent element results in numerous kinds of asymmetries. The following examples can describe what the asymmetry is.

a) A dog is below a table.

b) A table is above a dog.

These two sentences profile the same propositional content, describing the locative relationship between "a dog" and "a table". However, they are distinct in semantics owing to the opposite figure/ground alignment, for the former takes "a dog" as the figure, while the latter describes "a table" as the figure. With different purposes and expression, people can take different objects in the 
same scene as the prominent part in order to satisfy their comprehension of this scene, and thus different language forms and expression ways are produces.

As the above mentioned, the translation process is also a process of cognition. Therefore, the prominence dimension is also of significance for the translation, that is, translators can conform to the same expression methods or make reasonable adjustments during the translation process. Owing to the different thinking ways, there are different prominent habits between Chinese people and western people, but the content of their expression is familiar. For example, "crocodile tears" can be translated into “假慈悲” or “鳄鱼的眼泪”. “假慈悲” takes the implied meaning of “crocodile tears” as the prominent part, that is the figure, while “鳄鱼的眼泪” considers the literal meaning as the prominent part. These two different translation methods take different part of "crocodile tears" as figure for different purposes. The former tends to make the easy comprehension of Chinese people, while the latter is apt to maintain the exotic flavor.

\section{Prominence and Translation of Social Dialect}

The novel Frog is filled with social dialects, which is significant for the understanding of the novel for western readers. According to prominence dimension, there are different prominent parts, that is, figure, to be construed for the author and translator for different purposes and expression habits. Translators can provide a remarkable translation version for the social dialect only if they can deal with the prominent part of the social dialect for specific purposes. Therefore, social dialect should be translated in light of the dimension of prominence in Construal theory as well as the application of suitable translation methods in favor of the comprehension of the social dialect and the original. The following examples are studied aiming at illustrating that it is feasible for prominence dimension in Construal theory to explain how the social dialect translation should be translated with the help of suitable translation methods. With the suitable construal of social dialect, mistranslation can be avoided greatly and the meaning and feature of social dialect can be vividly enjoyed by western readers.

Example 1

但你姑姑的手五冬六夏都一样, 是软的, 凉的, 不是那种松垮的软, 是那种……怎么说呢…… 有文化的哥哥说：是不是像绵里藏针、柔中带刚？[8]

But your aunt's hands were always the same, whether in the cold of winter or the heat of summer: soft and cool, not spongy soft, more like ... How can I describe them? My educated elder brother said: Like a needle tucked into cotton, supple yet firm? [9]

This conversation with social dialect shows the different education level that my grandmother and my elder brother. The phases that my grandmother uses are simple and concise mixed with geographical characteristics, which is the feature of uneducated people's social dialect, such as “五 冬六夏”, “软的”, “凉的”, “松垮的软”. However, the phases that my elder brother uses are sophisticated with the use of Chinese four-character idiom, which is the feature of the social dialect of educated people, such as “绵里藏针” and “柔中带刚”. Goldblatt chooses simple expressions "whether in the cold of winter or the heat of summer", "soft and cool", "spongy soft" to render the “五冬六夏”, “软的”, “凉的”, “松垮的软” and sophisticated, vivid and more formal phases “like a needle tucked into cotton”, “supple yet firm” to render the expression “绵里藏针” and “柔中带刚”. Because the characteristics of these two different social dialects are the prominent parts in the original work, and Goldblatt chooses the literal translation method to transfer this kind of prominent part of the original into his translation version in order to present the characteristics of social dialects of different groups with guidance of prominence dimension.

Example 2

许多话他想说但不敢出口, 什么香火啦, 宗族啦, 对他这种人, 说出口就是罪过。[8]

He was incapable of describing the joy he felt. (There were terms like male heir and patriarchal clan, but from a man like him they would have been offensive.) [9]

The social dialect “香火” is generally used by the groups that who have affected by feudal idea, 
especially people in rural area, which refers in particular to the male heirs. In ancient China, people are influenced by feudal idea to desire the men to inherit the whole family and they call these men as “香火”. The prominent meaning of “香火” is the “male” heir instead of “female” heir. Therefore, Goldblatt renders it into "male heir" with the application of liberal translation method in light of prominence dimension, highlighting the prominent part, that is, the gender of the heir. With the help of liberal translation method under the guidance of prominence dimension, the innovation of “香火” can be transfer to the western target reader which is beneficial to their understanding of this social dialect and the theme of the original.

Example 3

母亲念叨：这个袁腮，说是为你挑了个黄道吉日，看看，都快水漫金山了。[8]

Yuan Sai said he'd picked a fine, auspicious day for you to get married, Mother complained, but what we got was flooded streets. [9]

“黄道吉日” is the social dialect that used for the marriage, which refers to a good day for people to marry. The prominent part of this social dialect is the characteristics of this day, that is, "good, fine and auspicious”. Based on the prominence dimension, Goldblatt construes the implied meaning of “黄道吉日” and highlights the prominent part of this social dialect, that is, “fine and auspicious”, with the application of liberal translation method, which not only is beneficial to the comprehension of the social dialect for marriage, but also achieves the same construal of the original and the translation version.

\section{Example 4}

我连讽带刺地说: 夫人, 请入洞房吧！[8]

"Madam”, I said to Renmei with dripping sarcasm, "the wedding chamber awaits". [9]

“夫人” here is a formal, courtesy term for the women married, which is the social dialect used by their husband of rank. In English, there are many expressions for addressing a women, such as "miss", "Mrs.", "lady", "dear" and so on, however, the prominent part of the term is the formal and courtesy feature to describe a married women, and thus Goldbaltt chooses "madam" to translate the social dialect “夫人”, for “madam” in English is also the formal and polite term for addressing a woman. Goldblatt conveys the prominent part of the term through expressing the formal and courtesy feature of the social dialect with the application of literal translation method under the guidance of the prominent dimension. Western readers can comprehend the social dialect in the original easily and clearly from the translation version of Goldblatt.

\section{Example 5}

我是个算命先生，排八字，推阴阳，测凶吉，看风水，这是我的专长。[8]

I'm a fortune-teller who calculates fortunes by numbers, yin and yang, good and evil, and feng shui. [9]

“排八字”, “推阴阳”, “测凶吉” and “看风水” are social dialects of fortune-teller, used in the activities about fortune-telling. While Goldblatt translates these social dialects, he chooses different translation methods for different prominent purposes. As for “排八字” and “测凶吉”, he construes the meaning of these two social dialects and explains them as "calculates fortunes by numbers" and "good and evil" with the application of liberal translation method under the guidance of prominence dimension, which highlights the implied meaning of these two social dialects as the prominent part. While “阴阳” and “风水” are Chinese traditional substances which are gradually familiar to the western readers and thus Goldblatt adopts transliteration method in light of prominence dimension, which takes Chinese traditional culture of fortune-telling as the prominent part.

\section{Conclusion}

One of the features of Frog, social dialect, can provide the readers with the information about what status of the speaker is in one community, and the better construal and translation of social dialect is of great significance for the western readers' understanding the translation novel, which is worthy studying. Based on the prominence dimension in Construal theory, the prominent part (that is, 
figure) is different for different observers, owing to the different focus on the same substance. As for the same content or the same relationship, there can be various expressions. In terms of translation, which is also a cognitive process, different prominent habits for the same object exist between Chinese and western expressions owing to the cultural differentiation and different purpose. Therefore, suitable translation methods should be applied during the process of social dialect translation under the guidance of prominence dimension in Construal theory, such as literal translation, liberal translation, transliteration method, etc., which is useful for conveying the feature of social dialect correctly.

\section{References}

[1] Xu Fang, Xu Jun. Translation and Creativity-- Professor Xu Jun Talks about the Award of Mo Yan and his works Translation [J]. Fiction Comment, 2013 (2): 4-10. (In Chinese)

[2] Cihai. [M]. Shanghai: Shanghai Lexicographical Publishing House, 1979. (In Chinese)

[3] Catford, G. A Linguistic Theory of Translation: An Essay in Applied Linguistics [M]. London: Oxford University Press: OUP, 1965.

[4] Basil, Hatim and Ian Mason. Discourse and the Translator [M]. Shanghai: Shanghai Foreign Language Education Press, 2001.

[5] Wardhaugh, Ronald. An Introduction to Sociolinguistics [M]. Beijing: Foreign Language Teaching and Research Press, 2000.

[6] Langacker, R. W. Foundations of Cognitive Grammar (Vol. II): Descriptive Application [M]. Stanford, California: Stanford University Press, 1991.

[7] F. Ungerer, H.J. Schmid. An introduction to Cognitive Linguistics [M]. Beijing: Foreign Language Teaching and Research Press, 2001.

[8] Mo Yan. Wa [M]. Beijing: People’s Literature Publishing House, 2015. (In Chinese)

[9] Howard Goldblatt. Frog [M]. United Kingdom: Hamish Hamilton, 2014. 